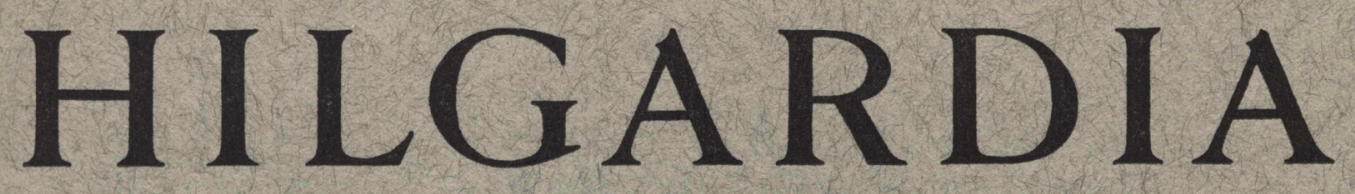

A Journal of Agricultural Science Published by the California Agricultural Experiment Station

\title{
RECLAMATION OF AN ALKALI SOIL OF THE HACIENDA SERIES
}

ROY OVERSTREET, J. C. MARTIN, R. K. SCHULZ, and O. D. MaCUTCHEON 
A "swamp culture" regime in which water grass was grown for several months under very moist conditions has proved to be an important factor in the reclamation of an alkali soil of the Hacienda series.

Gypsum applications of 4.22 and 12.47 tons per acre and sulfuric acid applications of 3.59 and 6.95 tons per acre, in conjunction with the swamp-culture pretreatment, showed marked beneficial effects on the subsequent growth of alfalfa.

Statistically, the sulfuric acid applications were more effective than the gypsum applications, although there were no significant differences in yield between the high and low acid treatments nor between the high and low gypsum treatments. This suggests that lower applications than 3.59 tons of sulfuric acid and 4.22 tons of gypsum may be equally effective. 


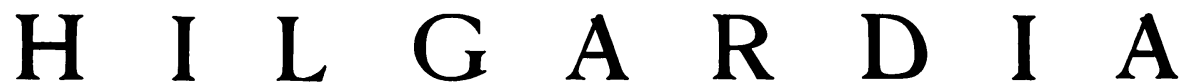

A Journal of Agricultural Science Published by

the California Agricultural Experiment Station

\begin{tabular}{lll}
\hline VoL. 24 & SEPTEMBER, 1955 & No. 3 \\
\hline
\end{tabular}

\section{RECLAMATION OF AN ALKALI SOIL OF THE HACIENDA SERIES ${ }^{1}$

\author{
ROY OVERSTREeT, J. C. MARTIN, R. K. SCHULZ, \\ and $O$. D. MCCUTCHEON ${ }^{2}$
}

\section{INTRODUCTION}

Numerous Reclamation experiments of the past have shown that alkali lands of the saline sodic type $e^{3}$ can be reclaimed by the liberal use of irrigation water alone, provided the soils are calcareous. The reclamation is all the more rapid if any sort of plant can be made to grow during the leaching procedure. For example, Kelley (1937) planted Bermuda grass on a soil at Kearney Vineyard which was highly toxic to barley and alfalfa because of high exchangeable sodium. The area was irrigated by the flooding method about twice each month for a period of two years. During this time the Bermuda grass grew fairly vigorously. Then barley seeds were sown, followed the next year by alfalfa. As a result of this practice exchangeable sodium was effectively replaced by calcium and high yields of alfalfa were eventually obtained. In fact, this procedure proved as effective in reclamation as the application of gypsum, sulfur, or acid salts. In his book, Alkali Soils, Kelley (1951) lists a number of plant species that ean be employed in such reclamation procedures and states that "advantage may be taken of almost any kind of plant that will grow in strongly alkaline soil." Also, in the reclamation experiments of Overstreet, Martin, and King (1951) near Kerman, California, it was observed that the plots which received no amendments were gradually reclaimed through leaching alone. Thus after a period of five years little difference in yield was apparent between the plots receiving water only and those receiving 10 tons per acre of gypsum, 5.7 tons per acre of sulfuric acid, and 1.9 tons per acre of sulfur. The upper photograph in figure 1, taken in the Kerman area in the fall of 1948, shows the growth of cotton before the reclamation experiments were initiated. The lower photograph, taken in the fall of 1954, shows the growth of cotton on the experimental area after

${ }^{1}$ Received for publication March 8, 1955.

$2 \mathrm{Mr}$. Overstreet is Professor of Soil Chemistry and Soil Chemist in the Experiment Station, Berkeley; Mr. Martin is Chemist in Plant Nutrition in the Experiment Station, Berkeley; Mr. Schulz is Assistant Specialist in the Experiment Station, Berkeley; and Mr. McCutcheon is Associate Agriculturist in Agricultural Extension, Hanford.

${ }^{3}$ The nomenclature used here is that adopted by Overstreet, Martin, and King (1951). 
the experiments were concluded. It is apparent that the growth is essentially uniform regardless of the treatment.

A number of factors are involved in the reclamation of calcareous alkali lands by the liberal use of water and the growth of tolerant plants. The majority of these are discussed by Kelley in his book Alkali Soils. However, they deserve further discussion here.

Firstly, a factor of major importance is soil structure. As is well known, when the salts have been leached from a saline sodic soil, the soil becomes dispersed and its permeability to water is markedly reduced. Moreover, on drying, the soil tends to form hard surface crusts which may seriously restrict the growth of young plants. This crusting may be prevented by the common practice of seeding into a moist seedbed and not irrigating until the

TABLE 1

\begin{tabular}{c|c|c|c}
\hline \hline $\begin{array}{c}\text { Days of } \\
\text { leaching }\end{array}$ & $\begin{array}{c}\text { Inches of } \\
\text { leaching }\end{array}$ & $\begin{array}{c}\text { Soluble Na, } \\
\text { m.e. per } \\
\text { 100 grams }\end{array}$ & $\begin{array}{c}\text { Exchangeable } \\
\text { sodium, } \\
\text { per cent }\end{array}$ \\
\hline 0 & 0 & 1.92 & 58.4 \\
8 & 0.6 & 0.85 & 53.8 \\
21 & 1.4 & 0.73 & 49.7 \\
47 & 3.3 & 0.53 & 40.6 \\
112 & 11.9 & 0.37 & 30.4 \\
\hline
\end{tabular}

plants are well established. However, if it becomes necessary to irrigate before the plants are established, or if it rains, frequent light applications of water may be required to ease the crusting problem. In some areas and with certain crops it is possible to seed in the fall of the year and thus take advantage of the cooler temperatures and moist conditions of the winter months for the establishment of the plants.

Secondly, the ample use of irrigation water on calcareous sodic soils results in the removal of adsorbed $\mathrm{Na}^{+}$ion and its replacement on the soil particles by $\mathrm{Ca}^{++}$ion. This is accomplished by the following reaction:

$$
2 \mathrm{Na}(a d)+\mathrm{H}_{2} \mathrm{O}+\mathrm{CaCO}_{3} \rightarrow \mathrm{Ca}(a d)+2 \mathrm{Na}^{+}+\mathrm{HCO}_{3}{ }^{-}+\mathrm{OH}^{-}
$$

where the suffix $(a d)$ refers to the adsorbed state. The soluble ions are removed from the root zone by the leaching water. Where some leaching can be accomplished, this hydrolysis reaction can be very important, as will be apparent from table 1 . The data of the table were obtained by leaching a calcareous sodic soil of the Hacienda series under a constant head of water in 5-gallon buckets. The analyses were made on the top 6 inches of soil.

Thirdly, when leaching can be accomplished in calcareous sodic soils where there is a cover of any sort of plant, the removal of adsorbed $\mathrm{Na}^{+}$and its replacement with $\mathrm{Ca}^{++}$is enhanced because of the carbon dioxide secreted by the roots. The behavior of the $\mathrm{CO}_{2}$ is described in the following reaction:

$$
\mathrm{CaCO}_{3}+\mathrm{CO}_{2}+2 \mathrm{Na}(a d)+\mathrm{H}_{2} \mathrm{O} \rightarrow \mathrm{Ca}(a d)+2 \mathrm{Na}^{+}+2 \mathrm{HCO}_{3}^{-}
$$

The soluble $\mathrm{Na}^{+}$and $\mathrm{HCO}_{3}{ }^{-}$ions are removed by the leaching water. The importance of this reaction in the reclamation process will depend greatly on 

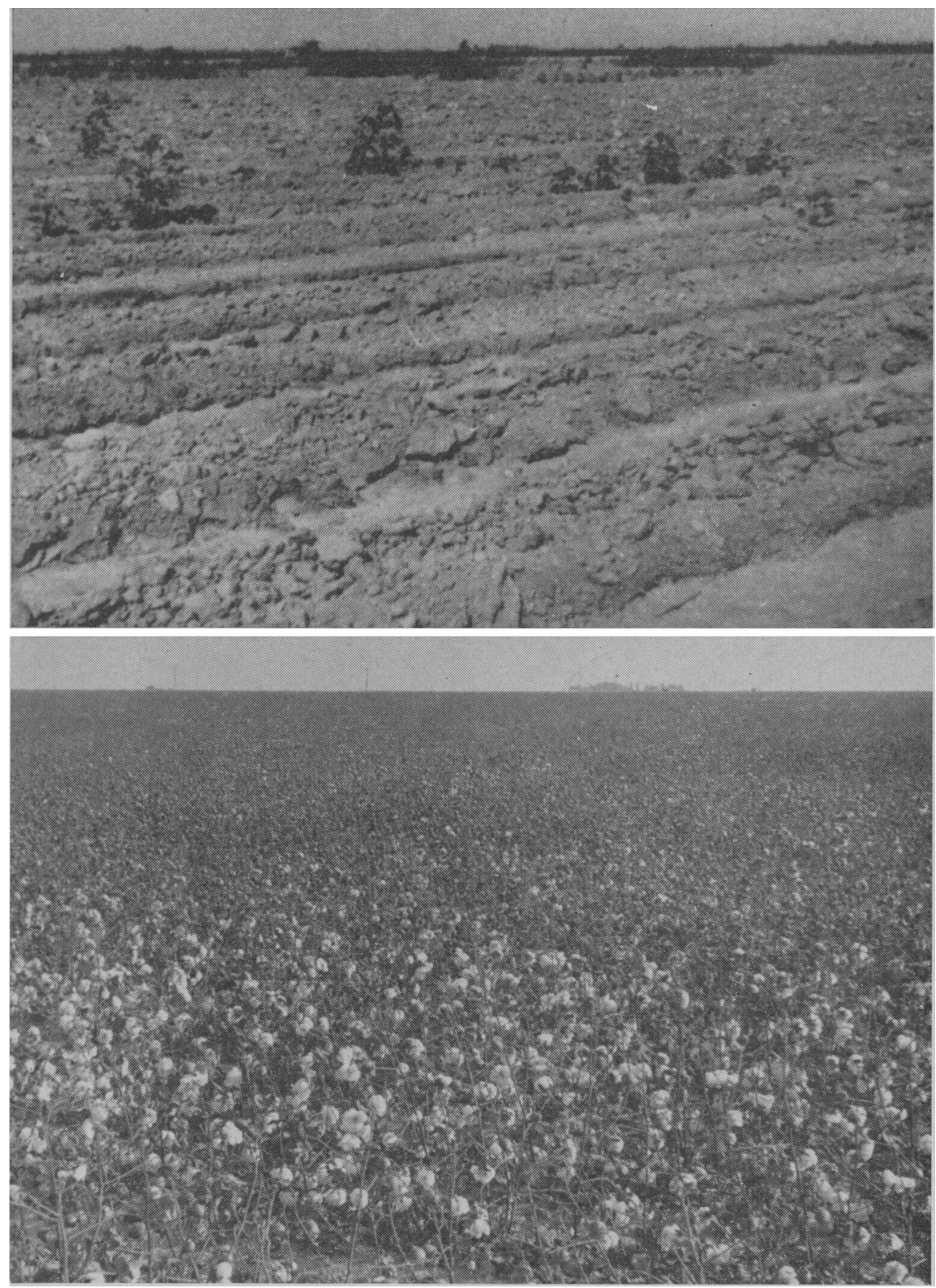

Fig. 1. Photographs of the experimental area on the C. H. Upton ranch near Kerman, California. The upper photograph, taken in the fall of 1948, shows the growth of cotton before the reclamation experiments were initiated. The lower photograph, taken in the fall of 1954, shows the growth of cotton after the experiments were concluded. The view includes plots leached only, those treated with sulfuric acid, and those treated with gypsum. 
the concentration of $\mathrm{CO}_{2}$ in the soil atmosphere. A number of investigations have shown that in the neighborhood of respiring plant roots the concentration of earbon dioxide in the soil atmosphere may vary from 10 to 1,000 times the concentration in the air above the soil (see, for example, Russell, 1952; Russell and Appleyard, 1915; and Boynton, Damon, and Compton, 1944).

In calcareous sodic soils, reclamation by way of the hydrolysis and $\mathrm{CO}_{2}$ reactions may be quite inexpensive. However, the efficiency of these reactions is greatly dependent on the percolation of water through the soil horizon. In the heavier sodic soils, leaching may be almost impossible to accomplish without the use of amendments. For this reason, the addition of certain amounts of gypsum, sulfuric acid, or sulfur may be essential. In general, the quantity of these chemicals required to effect the necessary leaching must be determined by trial in the field. The manner in which gypsum, sulfuric acid, and sulfur provide soluble $\mathrm{Ca}^{++}$ion and increase the permeability of calcareous sodic soils has been described by Kelley (1951) and in a previous article (Overstreet, Martin, and King, 1951).

In the present article, experiments dealing with the reclamation of a saline sodic soil of the Hacienda series are described. The results demonstrate the effectiveness in reclamation of the liberal use of irrigation water in the presence of a plant cover.

\section{SOIL CHARACTERISTICS}

The experiments were carried out on land belonging to the Corcoran Irrigation District three miles north of Corcoran, California. The plots are situated on the edge of the old Tulare Lake basin.

The soils of this basin are made up of sediments of granitic origin which were carried down from the Sierra Nevada by the Kings River. Thus the soil profiles are characterized by layers of varying texture.

Over the past seventy-five years, as the Kings River was utilized more and more for irrigation purposes, the lake gradually disappeared. This has left what is now known as the Tulare Lake basin, one of the most fertile areas of the Central Valley.

Unfortunately, through the process of wetting and drying, salts accumulated all around the rim of the basin, giving rise to the alkali soils of the Hacienda series. Although the water table at present is perhaps forty feet below the surface, the subsoil of the series is generally saline and the soil is characterized by high amounts of exchangeable sodium.

In extent, the Hacienda fine sandy loam comprises some 25 square miles around Corcoran. Near the plot area are some 2,500 acres of this soil belonging to the Corcoran Irrigation District. If one includes other members of the Hacienda series, which present slight textural variations as regards the compact horizon, the area represented is about 70 square miles in Kings and Tulare counties-70 square miles of soil which, if the excess sodium were removed, would be very productive. The general appearance of this land is shown in figure 2, a photograph of the land adjoining the plots.

Physically, the first 10 to 18 inches of the soil is a gray, porous, structureless, fine sandy loam which exhibits a soft lumpy condition when tilled. 
Below this, to a depth of three or four feet, there is an indurated layer, and this layer is impervious to water in its natural condition. Below this zone the soil is friable and sandy-appearing to a depth of at least five feet. Throughout the profile, fragments of shell occur.

Chemically, the surface of the soil is not excessively saline. The electrical conductivity of the saturation extract of the first foot varies between 1 and

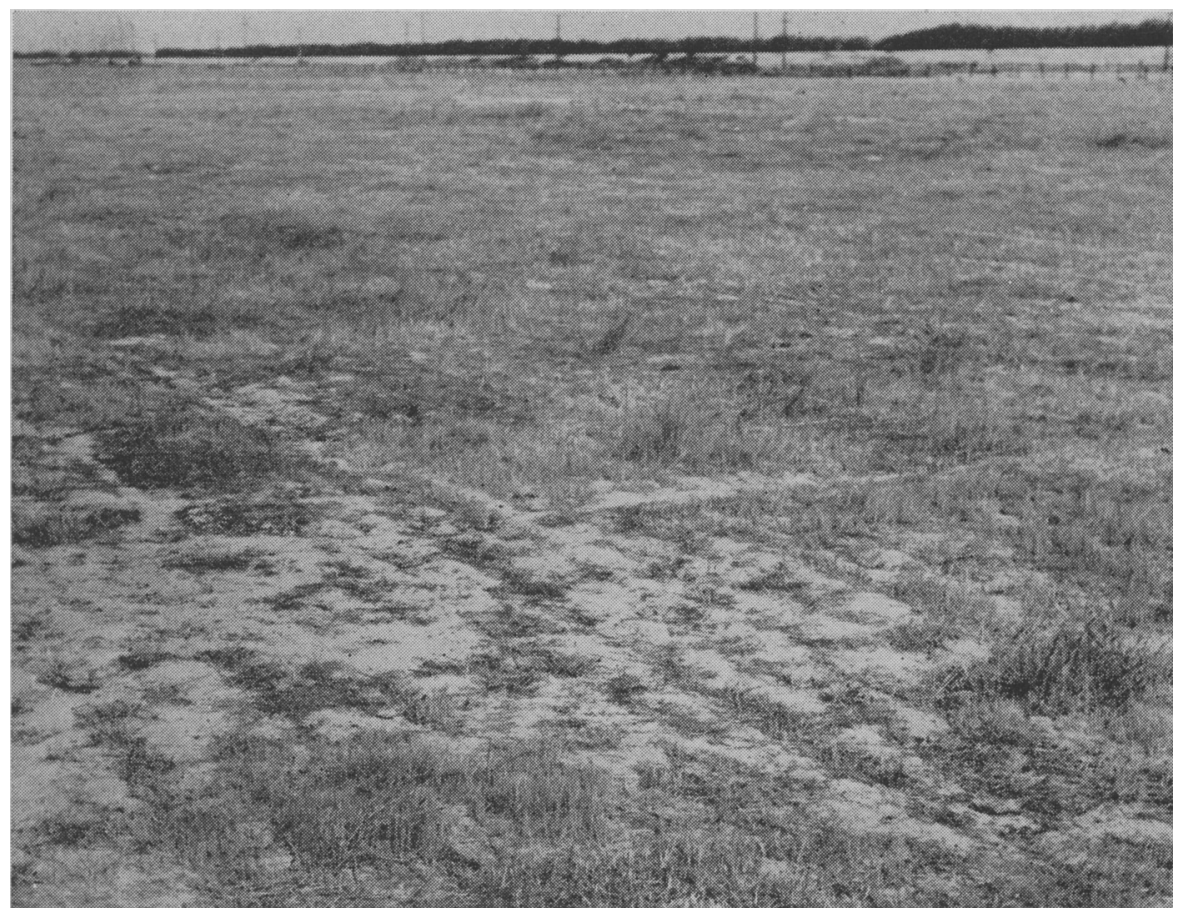

Fig. 2. Alkali soil of the Hacienda series: photograph of the land adjoining the plots near Corcoran, California.

6 millimhos per centimeter. At lower depths, the salinity generally increases and may correspond to as high as 15 millimhos per centimeter in the saturation extract. In the surface foot, the salt consists predominately of the bicarbonates, chlorides, and sulfates of sodium. The surface foot is virtually free of soluble carbonate, although this ion may become important at lower depths. The insoluble calcium carbonate percentage in the surface foot varies between 4 and 7.

The soil profile is characterized by high amounts of adsorbed sodium. The exchangeable sodium percentage in the first foot may vary between 25 and 85. Below this, the exchangeable sodium percentage may reach 100 .

The base-exchange capacity of the first foot is in the neighborhood of 11 milliequivalents per 100 grams oven-dry soil. In the indurated layer it may attain 16 milliequivalents per 100 grams oven-dry soil. 
In general, the soil is extremely variable chemically, even over very short distances. Table 2 is a chemical analysis of one of the many borings taken from the plot area and may be regarded as characteristic.

TABLE 2

ANALYSIS OF HACIENDA FINE SANDY LOAM SOIL FROM CORCORAN EXPERIMENTAL PLOTS

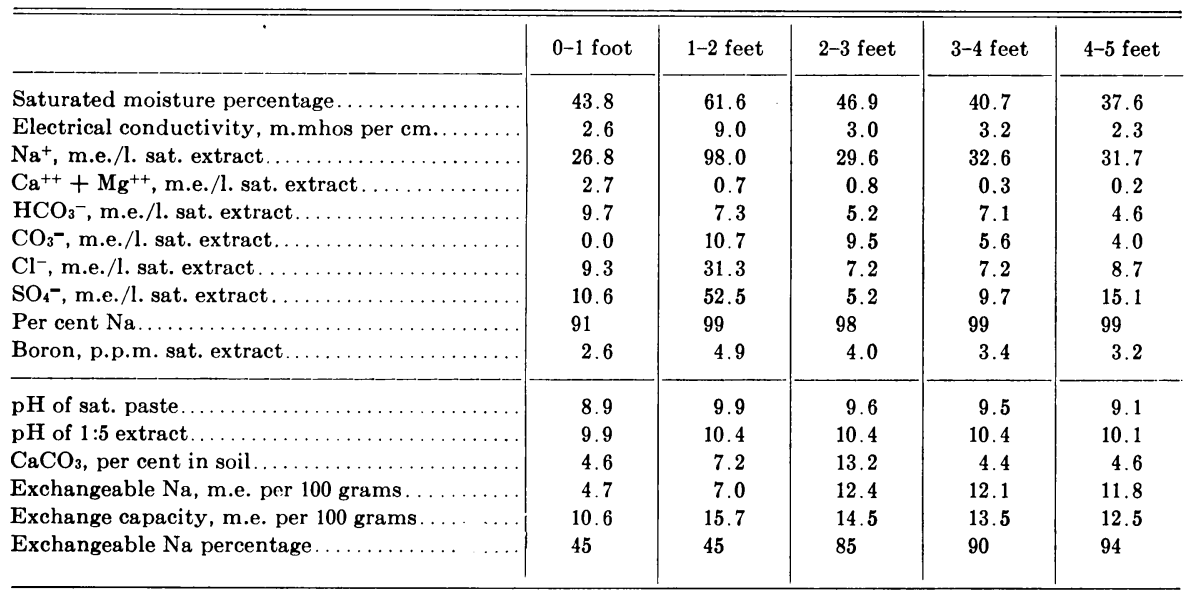

TABLE 3

ANALYSIS OF IRRIGATION WATER USED

AT CORCORAN PLOTS

$(\mathrm{pH}=8.0$; conductivity $=0.11 \mathrm{~m} . \mathrm{mhos}$ per $\mathrm{em})$

\begin{tabular}{|c|c|c|}
\hline Constituent & p.p.m. & m.e. per liter \\
\hline $\mathrm{Ca}^{++} \ldots \ldots \ldots \ldots \ldots \ldots \ldots$ & 10 & 0.5 \\
\hline $\mathbf{M g}^{++} \ldots \ldots \ldots \ldots \ldots \ldots$ & 5.0 & 0.1 \\
\hline $\mathrm{Na}^{+} \ldots \ldots$ & 35 & 1.5 \\
\hline $\mathrm{HCO}_{3}{ }^{-}$. & 70 & 1.1 \\
\hline $\mathrm{CO}_{3}-\ldots \ldots \ldots$ & 20 & 0.6 \\
\hline $\mathrm{Cl}^{-} \ldots \ldots \ldots \ldots \ldots \ldots \ldots$ & 10 & 0.3 \\
\hline $\mathrm{SO}_{4}-\ldots$ & $\mathbf{5}$ & 0.1 \\
\hline Boron $\ldots \ldots \ldots \ldots \ldots$ & 0.04 & \\
\hline
\end{tabular}

Sodium percentage $=71$

The irrigation water used in the reclamation experiments was obtained from a well situated about $3 / 4$ mile north of the plots. An analysis of this water is given in table 3 . It will be evident from the table that the water is low in total salts although the proportion of sodium to the total cations is somewhat high and there is a residual sodium carbonate content of about 1 milliequivalent per liter. 


\section{EXPERIMENTS}

On December 8,1950 , the field plots were laid out on the property of the Corcoran Irrigation District. Each plot was 30 feet wide and 145 feet long and was equal to 0.1 acres. In view of the rather high exchangeable sodium percentage in this soil, it was decided that substantial amounts of gypsum and sulfuric acid should be applied to permit the growth of alfalfa. Accordingly, the rates of 2 and 4 tons per acre of pure gypsum $\left(\mathrm{CaSO}_{4} \cdot 2 \mathrm{H}_{2} \mathrm{O}\right)$ were selected. Actually, the rates of 2.11 and 4.22 tons per acre of 97 per cent gypsum were applied. The intent was to apply the equivalent amounts (on

$\mathbf{N}$

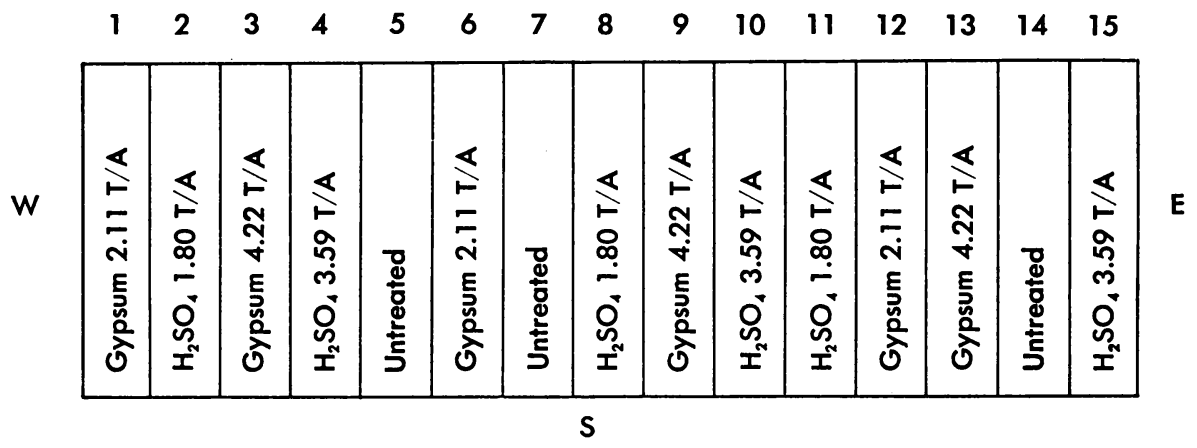

Fig. 3. Arrangement of the reclamation plots near Corcoran, California. Each plot was 30 feet wide and 145 feet long.

the basis of sulfur content) of 1.23 and 2.46 tons per acre of 93 per cent sulfuric acid. However, due to the large errors involved in applying the acid to small areas by means of a sprinkler truck, the amounts of 1.79 and 3.59 tons per acre of 93 per cent $\mathrm{H}_{2} \mathrm{SO}_{4}$ were actually applied.

The treatments were made on January 3 , 1951. Each treatment was replicated three times and the applications were randomized according to the scheme shown in figure 3.

The gypsum was applied by means of a conventional fertilizer spreader. The sulfuric acid was sprinkled on the plots in the concentrated form (93 per cent) by means of a special tank truck with a sprinkler devised from iron pipe by the Ake Brothers of Goshen, California.

After the application of the treatments, the plots were harrowed lightly to incorporate the amendments with the first 1 to 2 inches of soil.

The plots were irrigated six times between February 2 and 19, 1951. Approximately 3 inches of water was applied in each irrigation.

A seedbed was prepared in the middle of March and the plots were seeded to alfalfa on March 23, 1951.

Good germination of the alfalfa was obtained. After the plants were up, the plots were irrigated throughout the growing season on an average of once every 10 days. 
Unfortunately, as the hot weather came on, the soil exhibited a marked tendency to form a hard surface crust. Because of this, and in spite of the 10-day irrigations, only a small fraction of the alfalfa seedlings survived.

As the 1951 growing season progressed, the reclamation experiment was judged a complete failure. A very sparse stand of alfalfa was obtained on plots $3,4,9,10,13,14$, and 15 . A heavy growth of weeds, principally water-

TABLE 4

APPEARANCE OF CORCORAN PLOTS ON MAY 16,1952

\begin{tabular}{|c|c|c|}
\hline Plot no. & Treatment & Comment \\
\hline 1 & Gypsum, 2.11 tons per acre & $\begin{array}{l}\text { No alfalfa on south half; poor alfalfa on north half; sparse weeds and } \\
\text { grass on south half }\end{array}$ \\
\hline 2 & $\mathrm{H}_{2} \mathrm{SO}_{4}, 1.79$ tons per acre & $\begin{array}{l}\text { Poor alfalfa, weedy and wilted on south half; poor to fair alfalfa on } \\
\text { north half }\end{array}$ \\
\hline 3 & Gypsum, 4.22 tons per acre & Alfalfa fair to good; a few poor streaks; more than half good \\
\hline 4 & $\mathrm{H}_{2} \mathrm{SO}_{4}, 3.59$ tons per acre & Alfalfa fair to good-about half would be called good \\
\hline 5 & Untreated & Alfalfa poor and weedy; a few fair streaks \\
\hline 6 & Gypsum, 2.11 tons per acre & Alfalfa poor and weedy; a few fair streaks \\
\hline 7 & Untreated & Almost no alfalfa; sparse growth of grass and weeds \\
\hline 8 & $\mathrm{H}_{2} \mathrm{SO}_{4}, 1.79$ tons per acre & Mostly poor alfalfa; a few spots fair to good \\
\hline 9 & Gypsum, 4.22 tons per acre & About 60 per cent fair to good alfalfa; the rest poor to fair \\
\hline 10 & $\mathrm{H}_{2} \mathrm{SO}_{4}, 3.59$ tons per acre & About three-fourths fair to good alfalfa; the rest poor \\
\hline 11 & $\mathrm{H}_{2} \mathrm{SO}_{4}, 1.79$ tons per acre & Very poor alfalfa; mostly grass and weeds \\
\hline 12 & Gypsum, 2.11 tons per acre & Mostly poor alfalfa; a few small spots of fair alfalfa \\
\hline 13 & Gypsum, 4.22 tons per acre & About half fair to good alfalfa; the rest poor to fair \\
\hline 14 & Untreated & About half fair alfalfa; the rest poor and weedy \\
\hline 15 & $\mathrm{H}_{2} \mathrm{SO}_{4}, 3.59$ tons per acre & Plot well covered with fair to good alfalfa; about 50 per cent good \\
\hline
\end{tabular}

grass (Echinochloa crusgalli) and sprangletop (Leptochloa fascicularis), was evident over all of the plots. This condition was not improved by three cuttings made on June 20, August 8, and September 19.

In the early part of December, 1951, the plant cover was cut and removed. The soil was harrowed so as not to destroy the established alfalfa plants and the plots were reseeded to alfalfa.

A good germination of alfalfa was again obtained in the winter of 195152. As in 1951, the plots were irrigated about once every 10 days throughout the 1952 growing season.

Considerable improvement was noted in the plots during the spring of 1952. Nonetheless, the reclamation was considered far from satisfactory. The general appearance of the plots on May 16, 1952, is recorded in table 4 . 
With the oncoming of summer, the condition of the plots worsened. The alfalfa tended to die out and the proportion of weeds increased.

Six cuttings were made during the 1952 season, and the yields were recorded. The yields are not presented here because of the high percentage of weeds and because the yields showed no significant differences between treatments.

In December, 1952, the decision was made to try the effects of higher applications of gypsum and sulfuric acid to some of the plots. At the same time, cropping experiments were initiated at the Oxford Tract in Berkeley with a large sample of soil collected near the plots.

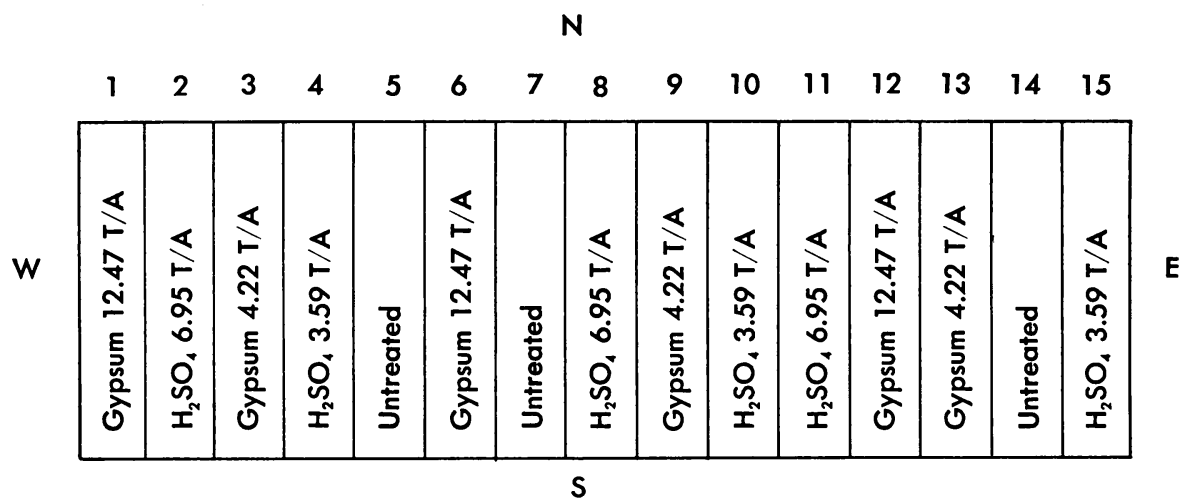

Fig. 4. Arrangement of Corcoran plots on February 25, 1953, after the second treatments with gypsum and sulfuric acid.

The plots were disked up in the period February 13-24, 1953. On February 25, gypsum was added to the plots which had received 2.11 tons per acre of gypsum so as to bring the total application up to 12.47 tons per acre. At the same time, sulfuric acid was added to the plots which had received 1.79 tons per acre of sulfuric acid so as to bring the total application to 6.95 tons per acre. Consequently, in terms of total applications of the amendments, the plots had the arrangement shown in figure 4.

The amendments were harrowed in and plots were irrigated three times during February and March. On April 1-3, 1953, a seedbed was prepared and the plots were seeded to alfalfa.

Good germination of the alfalfa was obtained. When the plants were up, the plots were irrigated every 10 days as formerly. With the onset of hot weather, the alfalfa plants died out progressively and by July, 1953, the appearance of the plots was even worse than in the 1952 season.

At this time, the conclusion was inescapable that under the usual irrigation and management practices, the application of totally uneconomical amounts of gypsum and sulfuric acid was not sufficient to reclaim the Hacienda soil at Corcoran.

Meanwhile, the cropping experiments at the Oxford Tract in Berkeley were showing results of considerable interest. 
As mentioned previously, these experiments were conducted with a large batch of soil collected from the Corcoran plot area. For each treatment, 40 pounds of the mixed soil was placed in a 5-gallon bucket which was provided with a drain. The amendment was then incorporated in the surface 2 inches of the soil and the soil was leached for one month. After the period of leaching the soil was seeded to alfalfa. After the seedlings emerged, the soil was watered by sprinkling frequently in such a way that a crust was never allowed to form.

The following applications were tried in the buckets: 1, 2, and 3 tons of

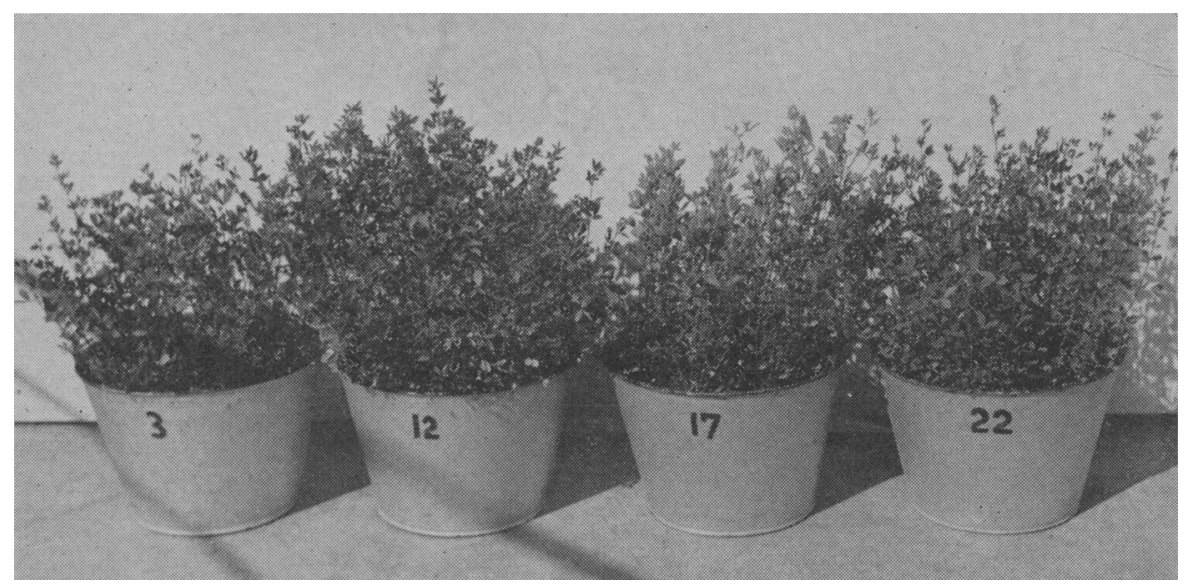

Fig. 5. Six-month-old alfalfa plants in the Oxford Tract experiments. Treatments from left to right: untreated (3), 9 tons per acre of sulfuric acid (12), 3 tons per acre of sulfur (17), and 15 tons per acre of gypsum (22).

sulfur per acre; 5, 10, and 15 tons of gypsum per acre; 3, 6, and 9 tons of sulfuric acid (100 per cent) per acre.

The amount of water percolating through the soils during the leaching period varied widely according to the treatment. Water was added to the buckets each day in amounts depending on the percolation rate. The untreated soils were ponded throughout the leaching period. In spite of this, only 2 to 3 inches of water passed through these soils in one month. The soils receiving the high applications of gypsum and sulfuric acid were subjected to many times this amount of leaching.

The unexpected result of the Oxford Tract experiments was that alfalfa grew equally well in all of the buckets. There were no significant differences in yield between the different treatments nor between the untreated and treated soils. This fact is illustrated in figure 5 .

Thus these results seemed to indicate that the Corcoran soil might be reclaimed merely by the liberal use of water plus a plant cover.

With this thought in mind, a new irrigation regime was initiated at the Corcoran plots. Starting in July, 1953, the plots were given a heavy irrigation every week or even more frequently. The soil was never allowed to dry 
out on the surface. As a result, the plots were soon covered with a heavy growth of water grass. It was thought, however, that this "swamp culture" might prove beneficial for the reasons discussed in the Introduction. Figure 6 shows the dense growth of water grass on one of the plots under these moist conditions.

The swamp culture was maintained until the latter part of October, 1953, at which time the plots were allowed to dry up. The water grass was then cut and removed. The stubble was sprayed with diesel oil and the plots were

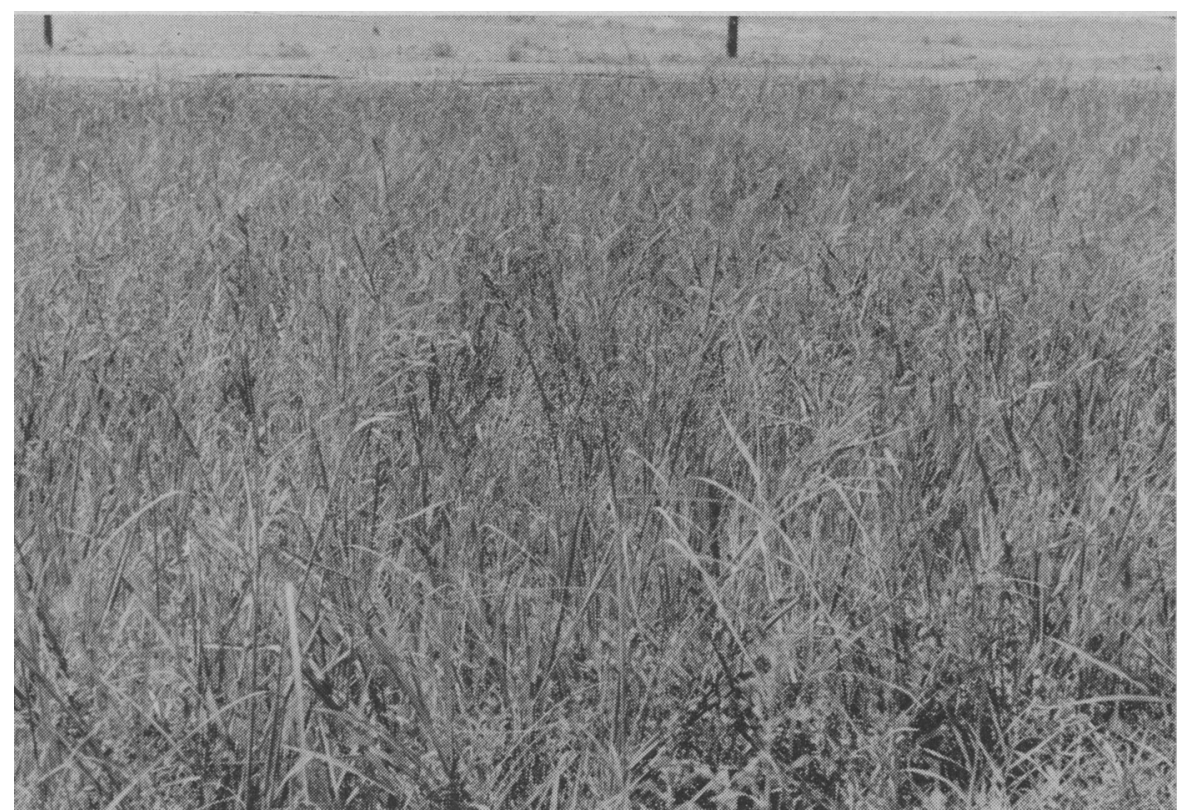

Fig. 6. Photograph of one of the Corcoran plots showing the dense growth of water grass under the "swamp culture" regime.

burned off so as to destroy the water-grass seeds. On December 27 a seedbed was prepared and on December 28 the plots were once more seeded to alfalfa.

As before, very good germination was obtained. On April 14 the plots were irrigated and thereafter they were irrigated about once a week. By late April the plots were covered with a very promising stand of alfalfa. A first cutting of hay was made on April 28, which served to eliminate certain varieties of weeds (mainly peppergrass, Lepidium nitidum). As the season progressed and the hot weather came on, the alfalfa died out to a large extent on the untreated plots 5 and 7 and water grass took over. However, on the rest of the plots the alfalfa continued to improve. A second cutting was made on July 1, 1954. At this time, the plots looked very good indeed and it was concluded that the area was well on the way to being reclaimed. A major problem remaining was the fact that most of the plots were made up of distinct patterns of excellent alfalfa and of fair to good alfalfa. 
The general appearance of the plots at the time of the July 1 cutting is recorded in table 5, and the yield data for this cutting is presented in table 6 . Photographs taken on July 1, 1954 are presented in figure 7. A third cutting was made September 7 .

TABLE 5

APPEARANCE OF CORCORAN PLOTS ON JULY 1, 1954

\begin{tabular}{|c|c|c|}
\hline Plot no. & Treatment & Comment \\
\hline 1 & Gypsum, 12.47 tons per acre & $\begin{array}{l}\text { Plot completely covered with fair to good alfalfa; good growth on } \mathrm{N} \\
\text { half; fair growth on } \mathrm{S} \text { half }\end{array}$ \\
\hline 2 & $\mathrm{H}_{2} \mathrm{SO}_{4}, 6.95$ tons per acre & Excellent stand of alfalfa over entire plot \\
\hline 3 & Gypsum, 4.22 tons per acre & $\begin{array}{l}\text { Plot nearly covered with good alfalfa; a few spots of stunted growth; } \\
\text { some weeds in stunted spots }\end{array}$ \\
\hline 4 & $\mathrm{H}_{2} \mathrm{SO}_{4}, 3.59$ tons per acre & Uniform stand of good alfalfa over entire plot \\
\hline 5 & Untreated & $\begin{array}{l}\text { Sparse, stunted alfalfa over most of plot; a spot of good alfalfa at } N \\
\text { end; weeds throughout the plot }\end{array}$ \\
\hline 6 & Gypsum, 12.47 tons per acre & Good stand of alfalfa over most of plot; a few spots of water grass \\
\hline 7 & Untreated & Plot covered with water grass; almost no alfalfa \\
\hline 8 & $\mathrm{H}_{2} \mathrm{SO}_{4}, 6.95$ tons per acre & Very good stand of alfalfa over entire plot \\
\hline 9 & Gypsum, 4.22 tons per acre & $\begin{array}{l}\text { Very good alfalfa on about half of the area; stunted alfalfa on rest } \\
\text { of plot }\end{array}$ \\
\hline 10 & $\mathrm{H}_{2} \mathrm{SO}_{4}, 3.59$ tons per acre & $\begin{array}{l}\text { Stand of good alfalfa over most of plot; a small area of stunted alfalfa } \\
\text { and weeds at } \mathrm{N} \text { end }\end{array}$ \\
\hline 11 & $\mathrm{H}_{2} \mathrm{SO}_{4}, 6.95$ tons per acre & Plot covered with stand of good alfalfa \\
\hline 12 & Gypsum, 12.47 tons per acre & Stand of fair alfalfa over entire plot \\
\hline 13 & Gypsum, 4.22 tons per acre & $\begin{array}{l}\text { Excellent alfalfa on } \mathrm{N} \text { half of plot; fair to good on } \mathrm{S} \text { half; some weeds } \\
\text { on } \mathrm{S} \text { end }\end{array}$ \\
\hline 14 & Untreated & $\begin{array}{l}\text { Excellent alfalfa on } \mathrm{N} \text { and } \mathrm{S} \text { ends; area of stunted alfalfa in center } \\
\text { of plot }\end{array}$ \\
\hline 15 & $\mathrm{H}_{2} \mathrm{SO}_{4}, 3.59$ tons per acre & $\begin{array}{l}\text { Uniform stand of fair alfalfa over whole plot; several spots of excel- } \\
\text { lent alfalfa; some weeds }\end{array}$ \\
\hline
\end{tabular}



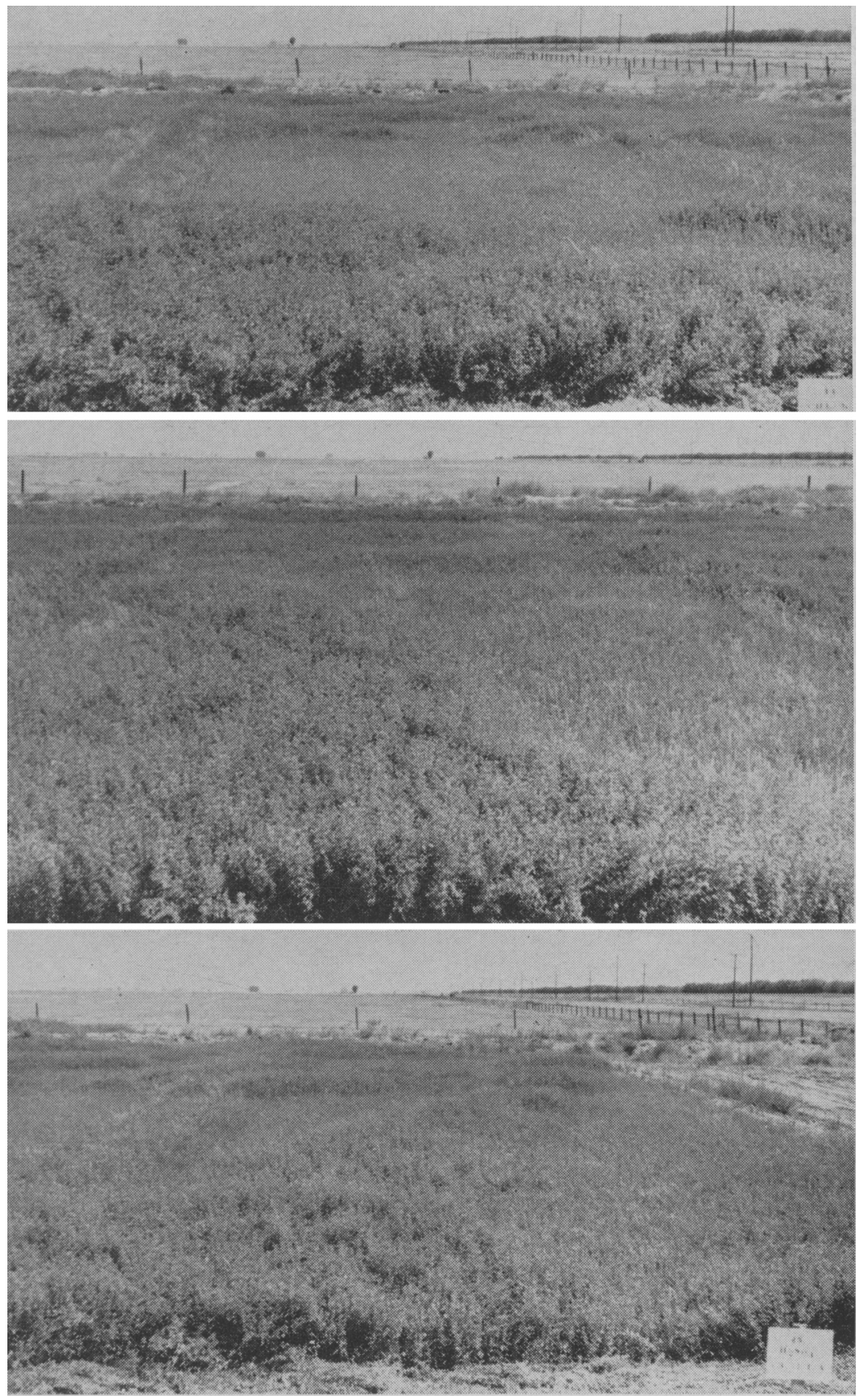

Fig. 7. Photographs taken on July 1, 1954, of plots at Corcoran, showing the effects of : no treatment (plot 14); 4.22 tons per acre of gypsum (plot 3 ); and 3.59 tons per acre of sulfuric acid (plot 15). The plots had been seeded to alfalfa on December 28, 1953. 
TABLE 6

YIELD DATA FOR CORCORAN PLOTS, CUTTING

OF JULY 1, 1954

(Air-dry weight $=24.7$ per cent of fresh weight)

\begin{tabular}{|c|c|c|}
\hline Treatment & Plot no. & $\begin{array}{l}\text { Yield of fresh } \\
\text { hay, } \\
\text { tons per acre }\end{array}$ \\
\hline Untreated. & $\begin{array}{r}5 \\
7 \\
14\end{array}$ & $\begin{array}{l}2.37 \\
0.11 \\
2.14\end{array}$ \\
\hline Gy psum, 4.22 tons per acre........... & $\begin{array}{r}3 \\
9 \\
13\end{array}$ & $\begin{array}{l}4.17 \\
3.35 \\
1.80\end{array}$ \\
\hline Gypsum, 12.47 tons per acre...... & $\begin{array}{r}1 \\
6 \\
12\end{array}$ & $\begin{array}{l}1.13 \\
2.97 \\
1.43\end{array}$ \\
\hline $\mathrm{H}_{2} \mathrm{SO}_{4}, 3.59$ tons per acre..... & $\begin{array}{r}4 \\
10 \\
15\end{array}$ & $\begin{array}{l}4.74 \\
4.17 \\
2.86\end{array}$ \\
\hline $\mathrm{H}_{2} \mathrm{SO}_{4}, 6.95$ tons per acre $\ldots \ldots \ldots \ldots \ldots$ & $\begin{array}{r}2 \\
8 \\
11\end{array}$ & $\begin{array}{l}5.98 \\
4.10 \\
5.19\end{array}$ \\
\hline
\end{tabular}




\section{DISCUSSION AND CONCLUSIONS}

The Corcoran field experiments, together with the bucket experiments at the Oxford Tract, indicate that a liberal use of irrigation water is of prime importance in the reclamation of soils of the Hacienda series. With the usual irrigation practices, it is apparent that reclamation is extremely slow even when relatively high amounts of amendments such as gypsum and sulfuric acid are applied.

The experiments suggest that in addition to the abundant use of water, the application of gypsum or sulfuric acid is beneficial. The observations of table 5 show that reclamation in the untreated plots has been considerably slower than in the treated plots, the alfalfa in the untreated plots being sparse and stunted and infested with weeds. The yield data of table 6 indicate that reclamation of untreated plot 7 has been particularly slow. It is apparent that plot 7 must be an unusually bad area in the field and this presents a serious difficulty in the statistical interpretation of the yield data. However, if the yield data of the treated plots are considered apart from those of the untreated plots, it emerges that the sulfuric acid treatments have been significantly more effective than the gypsum treatments. Also, on the same basis, there is no significant difference between the low and the high gypsum treatments nor between the low and high acid treatments. This suggests that under heavy irrigation lower applications of the amendments than those used in this experiment might have been equally effective.

The experiments at Corcoran indicate that the swamp-culture practice is quite effective in the reclamation of this type of soil, especially when gypsum or sulfuric acid are applied. Presumably, the water-grass cover is beneficial for the reasons discussed in the Introduction. The most economical applications of gypsum and sulfuric acid have not been determined with certainty. Evidently the maximum amounts of these amendments required are approximately 4 tons per acre of gypsum and 3.5 tons per acre of sulfuric acid.

An additional factor contributing to the success of the reclamation was undoubtedly the seeding of the alfalfa in the fall of the year. With this procedure the germination and seedling stages of the alfalfa were passed in a cool and moist climate which was similar to the conditions maintained in the bucket experiments at Berkeley.

In the Corcoran area, water is the cheapest amendment available: the current price of water in this area is $\$ 2.50$ per acre-foot; at present the price of gypsum is $\$ 16.50$ per ton and that of sulfuric acid is $\$ 47.50$ per ton.

In view of these prices, it appears highly desirable to investigate the effects on reclamation of other heavily irrigated plants such as sesbania, barnyard grass, and a variety of pasture plants. The effect of rice culture on reclamation also appears to be a very desirable study. Studies of this kind are now in progress in Kings and Tulare counties and will be reported later.

The Corcoran plots are to be continued and a special study will be made of the soil characteristics giving rise to the previously mentioned patterns of excellent alfalfa and of fair to good alfalfa. 


\section{LITERATURE CITED}

Boynton, Damon, and O. C. Compton

1944. Normal seasonal changes of oxygen and carbon dioxide percentages in gas from the larger pores of three orchard subsoils. Soil Science 57: 107-17.

KeLLEy, W. P.

1937. The reclamation of alkali soils. California Agr. Exp. Sta. Bul. 617: 1-40. (Out of print.)

1951. Alkali soils; their formation, properties and reclamation. vi $+176 \mathrm{p}$. Reinhold Publishing Corporation, New York, N. Y.

Overstreet, Roy, J. C. Martin, and H. M. King

1951. Gypsum, sulfur, and sulfuric acid for reclaiming an alkali soil of the Fresno series. Hilgardia 21: 113-27.

Russell, M. B.

1952. Soil aeration and plant growth. Ch. 4, p. 253-301, in: Joint Committee on Soil Tilth, American Society of Agronomy and American Society of Agricultural Engineers. Soil physical conditions and plant growth. Agronomy, vol. 2, xv + 491 p. Academic Press, Inc., New York, N. Y. (See especially p. 255.)

Russell, E. J., and A. Appleyard

1915. The atmosphere of the soil: its composition and the causes of variation. Jour. Agr. Sci. 7: 1-48. 
The journal Hilgardia is published at irregular intervals, in volumes of about 600 pages. The number of issues per volume varies.

Subscriptions are not sold. The periodical is sent as published only to libraries, or to institutions in foreign countries having publications to offer in exchange.

You may obtain a single copy of any issue free, as long as the supply lasts; please request by volume and issue number from:
Agricultural Publications
Room 22, Giannini Hall
University of California
Berkeley 4, California

The limit to nonresidents of California is 10 separate issues on a single order. A list of the issues still available will be sent on request. 
